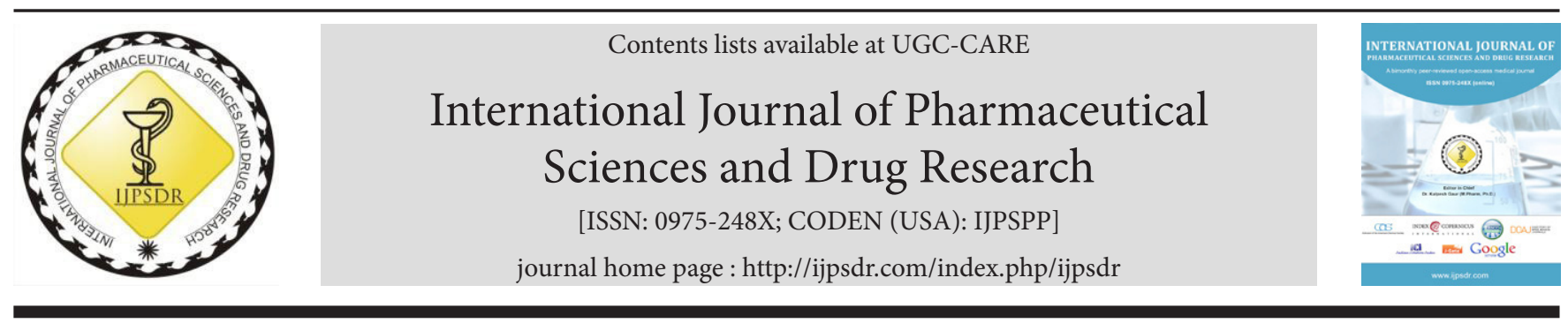

Research Article

\title{
Development and Validation of a Stability Indicating RP-HPLC Method for the Determination of Prucalopride succinate in Bulk and Tablet
}

\author{
Sangameshwar B. Kanthale ${ }^{1 *}$, Sanjay S. Thonte ${ }^{2}$, Sanjay S. Pekamwar ${ }^{1}$, Debarshi K. Mahapatra ${ }^{3}$ \\ ${ }^{1}$ School of Pharmacy, Swami Ramanand Teertha Marathwada University, Nanded-431606, Maharashtra, India \\ ${ }^{2}$ Channabasweshwar Pharmacy College, Latur-431512, Maharashtra, India \\ ${ }^{3}$ Department of Pharmaceutical Chemistry, Dadasaheb Balpande College of Pharmacy, Nagpur-440037, Maharashtra, India
}

\begin{tabular}{l} 
A R T I C L E I N F O \\
\hline Article history: \\
Received: 20 January, 2020 \\
Revised: 05 March, 2020 \\
Accepted: 13 March, 2020 \\
Published: 30 March, 2020 \\
Keywords: \\
Forced degradation, \\
Prucalopride succinate, \\
RP-HPLC, Tablet, \\
Validation, Stability. \\
D0I: \\
10.25004/IJPSDR.2020.120211
\end{tabular}

\begin{abstract}
A B S T R A C T
A very simple, precise, economical, accurate, robust, and reproducible reverse phase-high-performance liquid chromatography method along with stability-indicating attributes has been developed for estimating of prucalopride (PRU) succinate in both bulk and tablet formulation (PRUVICT 2). The estimation of the solutes was performed on a Grace $\mathrm{C}_{18}$ column of dimension $150 \mathrm{~mm} \times 4.6 \mathrm{~mm}, 5 \mu \mathrm{m}$. PRU was eluted with acetonitrile: $0.02 \mathrm{M}$ potassium dihydrogen phosphate in the ratio of $20: 80 \mathrm{v} / \mathrm{v}$ in a $10 \mathrm{~min}$ isocratic mode at a flow rate of $1 \mathrm{~mL} / \mathrm{min}$ at $30^{\circ} \mathrm{C}$ column temperature and monitored at a wavelength of $277 \mathrm{~nm}$. The retention time of PRU was found to be 5.416 minutes. The Q2B validation of the analytical method revealed good linearity over the concentration range $2-12 \mu \mathrm{g} / \mathrm{mL}$ for PRU with $\mathrm{r}^{2}$ of 0.999 . The mean recovery $\%$ over the three tested ranges of 50,100 , and $150 \%$ were found to be $100.173,99.077$, and $98.575 \%$, respectively. In intra-day variability study, the \% RSDs was detected to be $0.754,1.032$, and 0.482 whereas the inter-day variability study demonstrated \% RSDs of $0.797,0.559$, and 0.524 , respectively. The acid, alkali, boiled water, hydrogen peroxide, dry heat, and UV radiations based stress studies presented the formation of a variety of characteristic degradation products. The developed analytical method may be employed for the routine analysis of PRU in bulk and tablet formulations.
\end{abstract}

\section{INTRODUCTION}

Prucalopride (PRU) (Fig. 1) (IUPAC name: 4-amino5-chloro-2,3-dihydro- $N$-[1-(3-methoxy propyl)-4piperidinyl]-7-benzofurancarboxamide butanedioate) is a dihydro benzofuran carboxamide derivative belonging to the family of benzofuran that selectively stimulates $5-\mathrm{HT}_{4}$ receptors and embodies enterokinetic activity. ${ }^{[1]}$ The PRU was first produced by Shire Development LLC Ltd., USA, and endorsed for application in Europe in the year 2009 and by the Food and Drug Administration (FDA) in the year 2018. ${ }^{[2]}$ It selectively performs an activity on the gut muscle wall, thus, helping to reinstate the regular working of the human bowel. ${ }^{[3]}$ In subjects suffering from chronic constipation, there was a lessening in small bowel transit time, an augmentation in the gastric emptying, and further swift colonic filling. ${ }^{[4]}$ There was an enhancement in the bowel motion frequency but no considerable consequence on the transit time of the colon. ${ }^{[5]}$ This medication is available as tablet products (1 or $2 \mathrm{mg}$ ) such as PRUVICT $2^{\circledR}$, MOTEGRITY ${ }^{\circledR}$, and

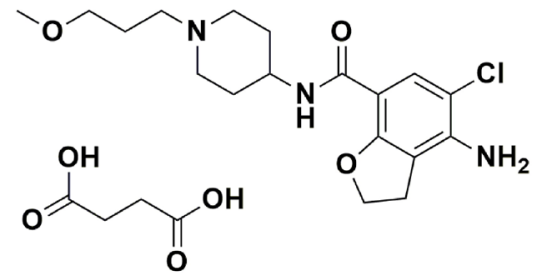

Fig. 1: Structure of prucalopride succinate

\footnotetext{
*Corresponding Author: Mr. Sangameshwar B. Kanthale

Address: School of Pharmacy, Swami Ramanand Teertha Marathwada University, Nanded 431606, Maharashtra, India

Email $\bowtie$ : sangamkanthale@gmail.com

Relevant conflicts of interest/financial disclosures: The authors declare that the research was conducted in the absence of any commercial or financial relationships that could be construed as a potential conflict of interest.

Copyright (C) 2020 Sangameshwar B. Kanthale et al. This is an open access article distributed under the terms of the Creative Commons AttributionNonCommercial-ShareAlike 4.0 International License which allows others to remix, tweak, and build upon the work non-commercially, as long as the author is credited and the new creations are licensed under the identical terms.
} 
RESOTRANS ${ }^{\circledR}$ for treating chronic idiopathic constipation (CIC) when other popular medications used in constipation do not provide any relief. ${ }^{[6,7]}$

While searching the literature available in the global pharmaceutical databases, not even a single data were reported regarding the stability-indicating validated RP-HPLC method for the routine analysis of PRU in bulk and pharmaceutical (tablet) formulation (PRUVICT 2). From the review of existing literature, it concluded that an analytical method is essentially required to routinely evaluate the quality attributes of PRU containing tablet formulations as well as in bulk form, so as to meet up the quality-related issues of any pharmaceutical industries that manufacture it. The present work focuses on the rational development of a validated stabilityindicating RP-HPLC method, which is very simple, precise, economical, accurate, robust, and reproducible for the determination of PRU in both tablet formulations and in bulk products.

\section{Materials AND METhODS}

\section{Materials}

A gift sample of PRU was procured from SL Drugs and Pharmaceuticals Ltd., Hyderabad. Analytical grade chemicals ( $30 \% \mathrm{v} / \mathrm{v} \mathrm{H}_{2} \mathrm{O}_{2}$, etc.), reagents $(\mathrm{NaOH}, \mathrm{HCl}$, etc.), and solvents (acetonitrile, potassium dihydrogen orthophosphate, etc.) were purchased exclusively from HiMedia Ltd., Mumbai. PRUVICT 2 (Torrent Pharmaceuticals Ltd., India)-each film-coated tablet contains PRU equivalent to $2 \mathrm{mg}$ of PRU was purchased from a local pharmacy shop at Nanded, Maharashtra.

\section{Instruments}

VSI ${ }^{\circledR}$ VSI-1B digital pH meter was employed for the estimation of solution $\mathrm{pH}$. Weighing of the chemicals was done using Shimadzu ${ }^{\circledR}$ AUW220D (Kyoto, Japan) balance. Transonic Digital S sonicator was utilized for the sonication. The photostability chamber (Newtronic ${ }^{\circledR}$ Model IC DAC v.1.2) was used for the forced degradation study. Elga Lab (PURELAB UHQ-II) water purification system provided the distilled water for the experiment. The method was developed on a Grace $\mathrm{C}_{18}$ column (250 $\times 4.6 \mathrm{~mm}$ i.d., $5 \mu \mathrm{m}$ particle size) connected to a Jasco HPLC system equipped with JASCO UV 2075 Plus detector having rheodyne sample injection port with $20 \mu \mathrm{L}$ loop. The chromatographic system was controlled by Empower v.2 software for the elution.

\section{Selection of the Mobile Phase}

The appropriate selection of a mobile phase is very crucial for the separation of drugs from a mixture. Based on the peak purity index, theoretical plates, and symmetry of peaks, the mobile phase was chosen. The trial was initiated employing the buffer systems along with acetonitrile (ACN). The elution with ACN:water in the ratio of 50:50 $\mathrm{v} / \mathrm{v}$ (poor peak shape and tailing; Rt = $9.1 \mathrm{~min}$ ) (Fig. 2a), $60: 40 \mathrm{v} / \mathrm{v}$ (poor peak shape with doublet; Rt = $7.12 \mathrm{~min}$ ) (Fig. 2b), and 70:30 v/v (broad peak; Rt = $3.56 \mathrm{~min}$ ) (Fig. 2c) showed either very short or too long duration and thus are unsuitable. Further use of ammonium acetate:ACN (50:50 $\mathrm{v} / \mathrm{v}$ ) did not improve the peak, rather peak splitting with broad peak shape was perceived ( $\mathrm{Rt}=7.1$ and $8.05 \mathrm{~min}$ ) (Fig. 2d). Changing the buffer from ammonium acetate to phosphate buffer $(0.02 \mathrm{M}): \operatorname{ACN}(70: 30 \mathrm{v} / \mathrm{v})$ resulted

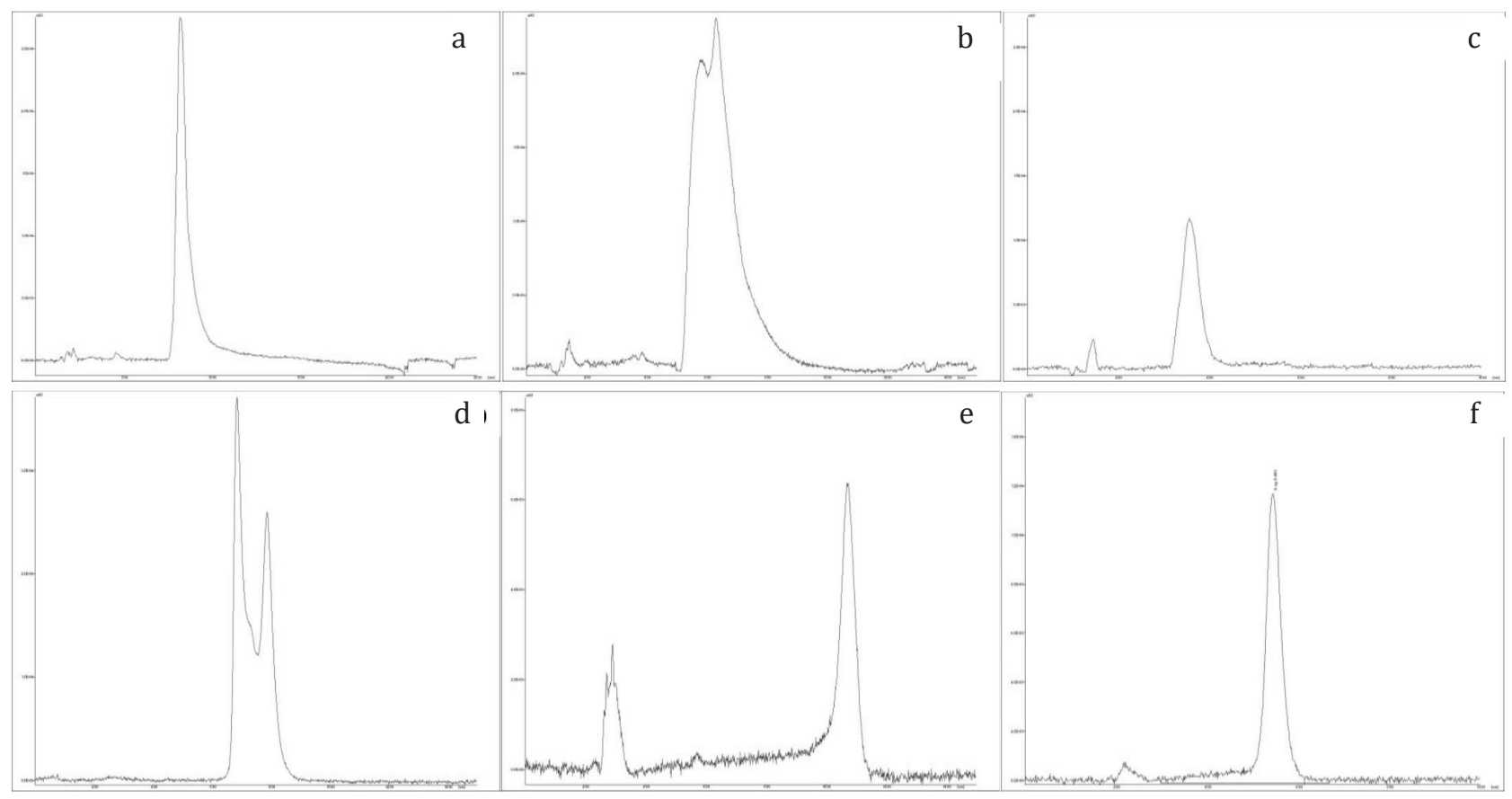

Fig. 2: Selection of mobile phase: (a) ACN:water (50:50 v/v); (b) ACN:water (60:40 v/v); (c) ACN:water (70:30 v/v); (d) Ammonium acetate:ACN (50:50 v/v); (e) Phosphate buffer (0.02 M): ACN (70:30 v/v); and (f) ACN: Phosphate buffer (0.02 M) (20:80 v/v). 
in a poor peak with peak tailing (Fig. 2e). Ultimately, the composition ACN: phosphate buffer $(0.02 \mathrm{M})(20: 80$ $\mathrm{v} / \mathrm{v}$ ) was selected for the elution (Fig. 2f). A sharp peak with ideal Gaussian characteristics was predominantly seen. The composition presented the largest number of theoretical plates and the highest peak purity index. The mobile phase content was then degassed under vacuum, filtered through a membrane filter $(0.45 \mu \mathrm{m})$, and allowed to equilibrate until a steady baseline was achieved.

\section{Determination of Wavelength}

From the standard stock solution (B), few dilutions were prepared using the diluent, and the content was scanned over the range of $400-200 \mathrm{~nm}$. The spectrum was obtained with prominent absorbances 227, 254, 277, 296, and $309 \mathrm{~nm}$. It was observed that the drug showed the highest absorbance $(\lambda \max )$ at $277 \mathrm{~nm}$, and thus selected for the analysis (Fig. 3).

\section{Chromatographic Conditions}

The PRU was eluted with acetonitrile: $0.02 \mathrm{M}$ potassium dihydrogen phosphate in the ratio of $20: 80 \mathrm{v} / \mathrm{v}$ in a $10 \mathrm{~min}$ isocratic mode at a flow rate of $1 \mathrm{~mL} / \mathrm{min}$ at $30^{\circ} \mathrm{C}$ column temperature and monitored at a wavelength of $277 \mathrm{~nm}$.

\section{Preparation of Analytical Solutions}

\section{Preparation of 0.02M Potassium Dihydrogen Phosphate}

$0.02 \mathrm{M}$ buffer was prepared by dissolving $2.72 \mathrm{gm}$ of potassium dihydrogen phosphate in sufficient HPLC grade water to produce $1000 \mathrm{~mL}$.

\section{Preparation of the Mobile Phase}

The mobile phase was composed by mixing $0.02 \mathrm{M}$ potassium dihydrogen phosphate buffer and acetonitrile in $80: 20 \mathrm{v} / \mathrm{v}$ ratios. The content was then filtered through a membrane filter $(0.45 \mu \mathrm{m})$ using a vacuum filtration assembly and further sonicated on an ultrasonic water bath for the duration of 15 minutes.

\section{Preparation of Standard Stock Solution}

The standard stock solution of PRU was prepared by dissolving $10 \mathrm{mg}$ of drug in $10 \mathrm{~mL}$ of ACN to get the desired

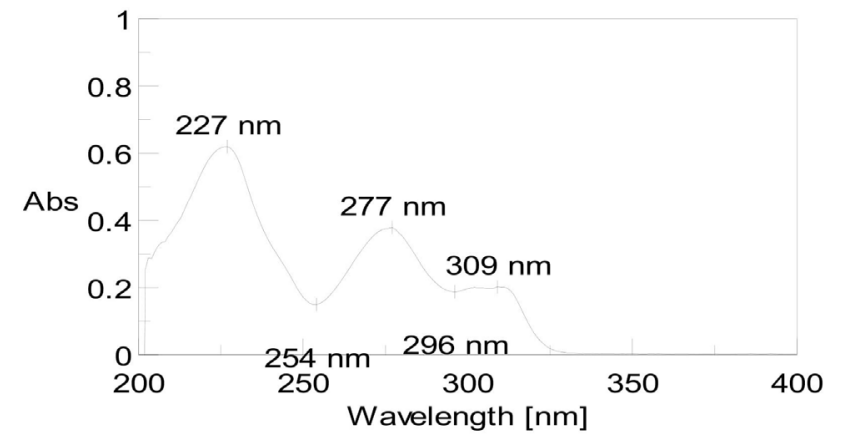

Fig. 3: UV spectrum of prucalopride succinate. concentration of $1000 \mu \mathrm{g} / \mathrm{mL}$ (A). From the standard stock solution, the standard working solution of PRU was prepared in ACN, which formed a resultant concentration of $100 \mu \mathrm{g} / \mathrm{mL}$ (B). Further dilution was made in ACN from the standard working solution to get the final solution of PRU $(10 \mu \mathrm{g} / \mathrm{mL})(\mathrm{C})$.

\section{Preparation of Sample Solution (Formulation Analysis)}

20 tablets of Pruvict 2 containing $2 \mathrm{mg}$ prucalopride were weighed and powdered uniformly. In a volumetric flask, $10 \mathrm{mg}$ equivalent of PRU was taken, diluent was half-filled, and sonicated further for the duration of $10 \mathrm{~min}$. The resulting sample stock solution was then filtered with Whatman filter paper 41 , and the volume was made by the dilute to the required mark to produce $1000 \mu \mathrm{g} / \mathrm{mL}$ strength. Further, $10 \mu \mathrm{g} / \mathrm{mL}$ concentration was prepared by dilution with the diluent.

\section{Method Validation}

The validation of the developed analytical method was achieved according to the International Council for Harmonization of Technical Requirements for Pharmaceuticals for Human Use (ICH) guidelines Q2A (Validation of analytical methods: definitions and terminology-presents a discussion of the characteristics for consideration during the validation of the analytical procedures) and Q2B (Validation of analytical procedures: methodology-presents a discussion of the characteristics that should be considered during the validation of analytical procedures) along with the compliance towards USFDA guidance.

\section{Linearity and Range}

In the concentration range of $2-12 \mu \mathrm{g} / \mathrm{mL}$, the linearity of the developed analytical method was determined by spiking six concentrations of PRU (equivalent volume) in the chromatographic HPLC system. The peak area of the method was estimated after preparing the solutions in the presence of the diluent. The linearity graph was formed by plotting the average area against the concentration for each drug solution. The linear regression equation and the regression coefficient value $\left(\mathrm{r}^{2}\right)$ were established. ${ }^{[8]}$

\section{Accuracy}

The recovery data (accuracy) was determined at concentration levels of 50,100 , and $150 \%$ by spiking the standard drug solutions in the HPLC system. On the basis of definite concentrations, the study was conducted in a triplicate manner and data were reported as \% recovery $\pm \%$ relative error. ${ }^{[9]}$

\section{Precision}

The precision data was determined at a concentration of 6 , $8,10 \mu \mathrm{g} / \mathrm{mL}$ by spiking the standard drug solutions in the HPLC system for intra-day (six times in a single day) and inter-day (three different days). The study was conducted 
in a triplicate manner and data were reported as precision $\pm \%$ relative error. ${ }^{[10]}$

\section{Robustness}

The robustness was determined for the developed chromatographic method by making deliberate changes in the conditions such as alteration in flow rate [at $0.9 \mathrm{~mL} /$ $\min (-1)$ and $1.1 \mathrm{~mL} / \mathrm{min}(+1)]$; wavelength [at $275 \mathrm{~nm} \mathrm{(-2)}$ and $279 \mathrm{~nm}(+2)]$; and mobile phase composition $[18: 82 \mathrm{v} / \mathrm{v}$ $(-2:+2)$ and $22: 78 \mathrm{v} / \mathrm{v}(+2:-2)]$. The other parameters such as column temperature, column length, and its composition, etc., were kept fairly constant. ${ }^{[11]}$

\section{Systems Suitability Parameters}

The systems suitability parameters are determined by injecting the standard solution 5 times in the HPLC system and further determining the imperative components like tailing factor, peak area, retention time, and theoretical plates. This parameter is a measure of the reproducibility attribute of any developed chromatographic method. ${ }^{[12]}$

\section{Limit of Detection}

The limit of detection (LoD) is said to be the lowest possible concentration that can be detected by any sophisticated analytical method; however, it is not always essential to estimate the exact amount of the solute precisely. ${ }^{[13]}$ The given formula determines it:

$$
\mathrm{LoD}=3.3(\sigma / \mathrm{S})
$$

Where $\sigma=$ standard deviation of response; $S=$ slope of the calibration curve. The slope $S$ may be estimated from the calibration curve of the analyte.

\section{Limit of Quantification}

The limit of quantification (LoQ) is said to be the lowest possible concentration that can be detected by any sophisticated analytical method, however, with a significant level of precision and accuracy. ${ }^{[14]}$ The given formula determines it:

$$
\mathrm{LoQ}=10(\sigma / \mathrm{S})
$$

Where $\sigma=$ standard deviation of response; $\mathrm{S}=$ slope of the calibration curve. The slope $S$ may be estimated from the calibration curve of the analyte.

\section{Degradation Studies}

The forced degradation studies under the conditions of acid, alkali, boiled water, hydrogen peroxide, dry heat, and UV radiations were performed according to the procedure given by Kanthale et al., 2019.[15]

\section{Acid Degradation Studies}

A total of $0.5 \mathrm{mg}$ of equivalent drug was taken in a volumetric flask and diluent was added to half-level. The content was further sonicated (10-15 min) to make the solution clear and to remove the dissolved gases. The content was then filled with the residual diluent quantity to make up the volume up to $100 \mathrm{~mL}$. The above content was stirred for $30 \mathrm{~min}$ using a stirrer and afterward centrifuged at $3000 \mathrm{rpm}$ for $5 \mathrm{~min}$ duration. From the prepared solution, $5 \mathrm{~mL}$ of the sample was taken and mixed with $5 \mathrm{~mL}$ of $2 \mathrm{~N} \mathrm{HCl}$. The mixture was boiled for an hour under a water bath and further neutralized by an equal volume of $2 \mathrm{~N} \mathrm{NaOH}$. The volume was made up to $100 \mathrm{~mL}$ and filtered through the membrane filter $(0.45 \mu \mathrm{m}) .20 \mu \mathrm{L}$ of the above content was spiked into the system and data were witnessed.

\section{Alkali Degradation Studies}

A $0.5 \mathrm{mg}$ of equivalent drug was taken in a volumetric flask and diluent was added to half-level. The content was further sonicated (10-15 $\mathrm{min}$ ) to make the solution clear and to remove the dissolved gases. The content was then filled with the residual diluent quantity to make up the volume up to $100 \mathrm{~mL}$. The above content was stirred for 30 minutes using a stirrer and afterward centrifuged at $3000 \mathrm{rpm}$ for 5 minutes duration. From the prepared solution, $5 \mathrm{~mL}$ of the sample was taken and mixed with $5 \mathrm{~mL}$ of $2 \mathrm{~N} \mathrm{NaOH}$. The mixture was boiled for an hour under a water bath and further neutralized by an equal volume of $2 \mathrm{~N} \mathrm{HCl}$. The volume was made up to $100 \mathrm{~mL}$ and filtered through the membrane filter $(0.45 \mu \mathrm{m}) .20 \mu \mathrm{L}$ of the above content was spiked into the system and the data was witnessed.

\section{Neutral Hydrolysis Studies}

$0.5 \mathrm{mg}$ of equivalent drug was taken in a volumetric flask and diluent was added to half-level. The content was further sonicated (10-15 min) to make the solution clear and to remove the dissolved gases. The content was then filled with the residual diluent quantity to make up the volume up to $100 \mathrm{~mL}$. The above content was stirred for 30 min using a stirrer and afterward centrifuged at 3000 rpm for 5 min duration. From the prepared solution, 5 $\mathrm{mL}$ of the sample was taken, boiled for an hour under a water bath, and the volume was made up to $100 \mathrm{~mL}$. The above content was filtered through the membrane filter $(0.45 \mu \mathrm{m}), 20 \mu \mathrm{L}$ of the above content was spiked into the system, and the data was witnessed.

\section{Oxidation Degradation Studies}

$0.5 \mathrm{mg}$ of equivalent drug was dissolved in $\mathrm{H}_{2} \mathrm{O}_{2}(5 \mathrm{~mL})$ and boiled for $1 \mathrm{hr}$ duration in a volumetric flask to commence the oxidative stress on the drug molecule. By using the diluent, the above reaction content was diluted and the volume was made up to the mark. Further, the above content was centrifuged at 3,000 rpm for 5 minutes duration, and the supernatant was collected. A $20 \mu \mathrm{L}$ of the above content was spiked into the system and the data was witnessed.

\section{Dry Heat Degradation Studies}

A $0.5 \mathrm{mg}$ of the equivalent drug, taken in a petri dish, was exposed to dry heat in over at a temperature of $90 \pm 1^{\circ} \mathrm{C}$ for 1 hour. The content was added to a volumetric flask, and diluent was added to it. The above content was stirred for half 
an hour, sonicated for 10-15 min, and the volume was made up to $100 \mathrm{~mL}$. Further centrifugation was performed at 3,000 rpm for 5 minutes duration, filtered through the membrane filter $(0.45 \mu \mathrm{m})$, and spiked $(20 \mu \mathrm{L})$ into the HPLC system.

\section{UV-rays Induced Degradation Studies}

A $0.5 \mathrm{mg}$ of equivalent drug was placed in a petri dish and kept under the UV-chamber at $254 \mathrm{~nm}$ for the duration of 72 hours. After the UV exposure, the content was added to a volumetric flask and the diluent was added in a halffilled manner. The content in the volumetric flask was stirred uniformly for the duration of 30 minutes, further sonicated for 10-15 minutes, and the volume was made up to $100 \mathrm{~mL}$. The content was centrifuged at $3000 \mathrm{rpm}$ for 5 minutes, filtered through the membrane filter $(0.45 \mu \mathrm{m})$, and spiked $(20 \mu \mathrm{L})$ into the HPLC system to determine the degraded product(s).

\section{RESULTS AND DISCUSSION}

\section{Method Development and Optimization of Chromatographic Conditions}

The novel developed analytical method was based on several trials and errors and ultimately the best possible mobile phase (acetonitrile:0.02 M potassium dihydrogen phosphate in the ratio of 20:80 v/v) was selected for the chromatographic 10 min run on a Grace $C_{18}$ column $(250 \times 4.6 \mathrm{~mm}$ i.d., $5 \mu \mathrm{m}$ particle size $)$ at a flow rate of $1 \mathrm{~mL} / \mathrm{min}$ under ambient temperature $\left(30^{\circ} \mathrm{C}\right)$ and detected wavelength at $277 \mathrm{~nm}$. The selection of this $\mathrm{C}_{18}$ column was based on inspiration drawn from previous studies. The elution was achieved after several continuous trials run at 5.416 minutes (averagely) under isocratic mode (Fig. 4). A low $\mathrm{pH}$ was preferred in the mobile phase as it enables an acute reduction in the peak tailing, prevents the dissolution of silica-based reversed-phase columns, and remarkably improves the method robustness. The $\mathrm{pH}$ was made in a similar constitution with the pKa value to ascertain the solute in the unionized state, essential criteria for achieving high resolution. So, the $\mathrm{pH}=\mathrm{pKa}$ up to 2 units were chosen rationally. The short-time run will have several advantages in context to solvent and time. The tablet formulation sample assay provided a mean recovery of $99.17 \%$ with $\%$ RSD value of 1.172 (Table 1). The developed chromatographic method helped in routine analysis of drugs in bulk, very precisely, accurately, and with adequate robustness.

\section{Method Validation}

\section{Linearity and Range}

A high degree of linearity was found for PRU over the range of $2-12 \mu \mathrm{g} / \mathrm{mL}$ (Table 2 ). A linear range (regression coefficient value; $r^{2}=0.996$ ) was perceived between the concentration and the peak area with linear regression equation $y=31497 x+8257.3$ (Fig. 5).

\section{Accuracy}

From the formed calibration curve, the \% recovery of the drug PRU from the developed chromatographic method was estimated based on the slope of the graph

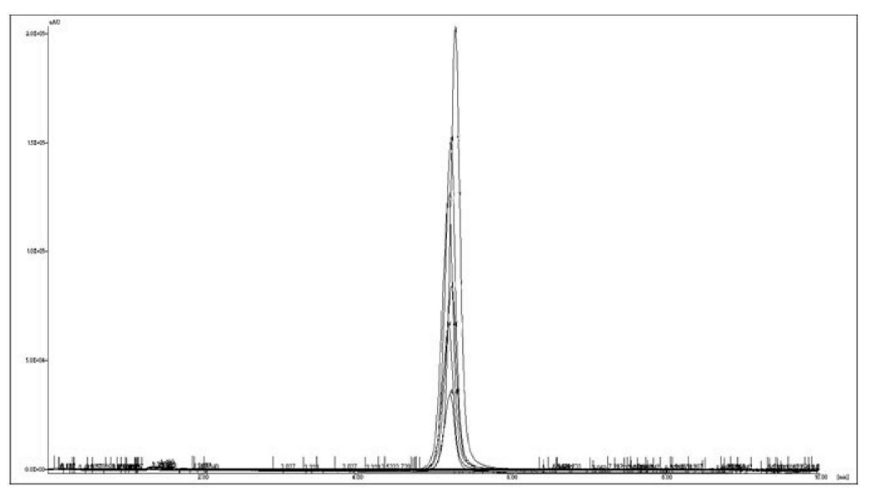

Fig. 4: Chromatogram of prucalopride succinate obtained from multiple sampling

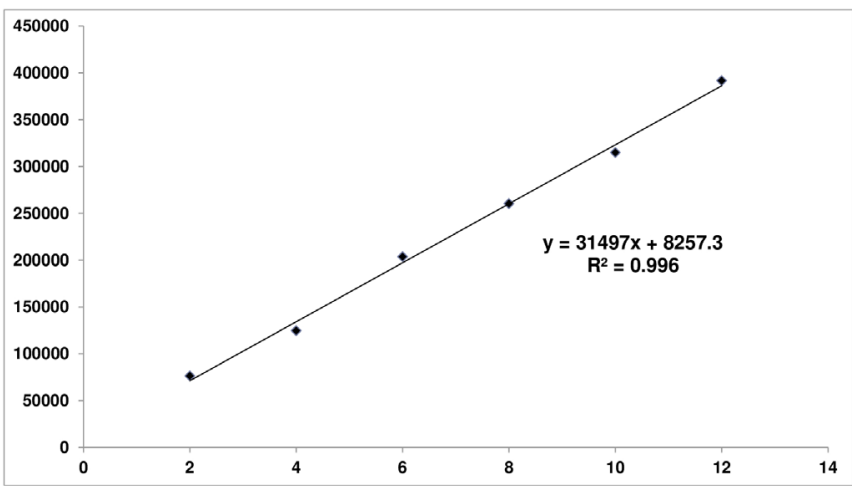

Fig. 5: Linearity plot of prucalopride succinate

Table 1: Assay performed for tablet formulation sample of prucalopride succinate

\begin{tabular}{llll}
\hline S. No. & $\begin{array}{l}\text { Peakarea } \\
(4 \mu \mathrm{g} / \mathrm{mL})\end{array}$ & $\begin{array}{l}\text { Amount recovered } \\
(\mu \mathrm{g} / \mathrm{mL})\end{array}$ & \% Recovery \\
\hline 1 & 136135 & 4.060 & 101.500 \\
2 & 132914 & 3.958 & 98.943 \\
3 & 133381 & 3.973 & 99.314 \\
4 & 132193 & 3.935 & 98.371 \\
5 & 133565 & 3.978 & 99.460 \\
6 & 135158 & 4.029 & 100.724 \\
Mean & 133891 & 3.989 & 99.719 \\
SD & 1472.75 & 0.047 & 1.169 \\
\% RSD & 1.09996 & 1.172 & 1.172 \\
\hline
\end{tabular}


Validated Stability-indicating RP-HPLC Method for Prucalopride Succinate

Table 2: Linearity study of prucalopride succinate

\begin{tabular}{|c|c|c|c|c|c|}
\hline $\begin{array}{l}\text { Conc. } \\
(\mu \mathrm{g} / \mathrm{mL})\end{array}$ & Replicates & Area & Mean & $S D$ & $\% R S D$ \\
\hline \multirow[t]{5}{*}{2} & 1 & 74890 & \multirow{5}{*}{76462} & \multirow{5}{*}{1369.939} & \multirow{5}{*}{1.792} \\
\hline & 2 & 78630 & & & \\
\hline & 3 & 75895 & & & \\
\hline & 4 & 76530 & & & \\
\hline & 5 & 76365 & & & \\
\hline \multirow[t]{5}{*}{4} & 1 & 123367 & \multirow{5}{*}{124788.6} & \multirow{5}{*}{2346.6} & \multirow{5}{*}{1.880} \\
\hline & 2 & 125193 & & & \\
\hline & 3 & 122465 & & & \\
\hline & 4 & 128564 & & & \\
\hline & 5 & 124354 & & & \\
\hline \multirow[t]{5}{*}{6} & 1 & 200993 & \multirow{5}{*}{203675} & \multirow{5}{*}{3026.817} & \multirow{5}{*}{1.486} \\
\hline & 2 & 204564 & & & \\
\hline & 3 & 201468 & & & \\
\hline & 4 & 202865 & & & \\
\hline & 5 & 208485 & & & \\
\hline \multirow[t]{5}{*}{8} & 1 & 265148 & \multirow{5}{*}{260540} & \multirow{5}{*}{4327.437} & \multirow{5}{*}{1.661} \\
\hline & 2 & 262489 & & & \\
\hline & 3 & 256412 & & & \\
\hline & 4 & 255460 & & & \\
\hline & 5 & 263191 & & & \\
\hline \multirow[t]{5}{*}{10} & 1 & 318986 & \multirow{5}{*}{315075.2} & \multirow{5}{*}{5707.997} & \multirow{5}{*}{1.812} \\
\hline & 2 & 322102 & & & \\
\hline & 3 & 307409 & & & \\
\hline & 4 & 312564 & & & \\
\hline & 5 & 314315 & & & \\
\hline \multirow[t]{5}{*}{12} & 1 & 398410 & \multirow{5}{*}{391874.2} & \multirow{5}{*}{6438.445} & \multirow{5}{*}{1.643} \\
\hline & 2 & 385272 & & & \\
\hline & 3 & 391456 & & & \\
\hline & 4 & 385823 & & & \\
\hline & 5 & 398410 & & & \\
\hline
\end{tabular}

and the Y-intercept, which played a prominent role. The $\%$ RSD values were found to be $0.755,0.588$, and 0.482 , respectively, which corresponded within the acceptance limit $( \pm 2 \%$ ) given in the USP pharmacopeia (Table 3 ).

\section{Precision}

The study comprising of both intra-day and inter-day variability represented considerably high precision over the tested PRU range of $6-10 \mu \mathrm{g} / \mathrm{mL}$. The peak area of the sample solution matched exactly with the standard solution, with \% RSD meeting the essential requirement of $<2 \%$. In intra-day variability study, the $\%$ RSDs were detect to be $0.754,1.032$, and 0.482 (Table 4), respectively, whereas the inter-day variability study demonstrated \% RSDs of $0.797,0.559$, and 0.524 (Table 5), respectively. The study highlighted minimum disparity

Table 3: Recovery for accuracy studies for prucalopride succinate

\begin{tabular}{|c|c|c|c|c|c|}
\hline Level & $\begin{array}{l}\text { Conc. of sample solution } \\
(\mu \mathrm{g} / \mathrm{mL})\end{array}$ & $\begin{array}{l}\text { Conc. of standard solution spiked } \\
(\mu \mathrm{g} / \mathrm{mL})\end{array}$ & Area & $\begin{array}{l}\text { Amount recovered } \\
(\mu \mathrm{g} / \mathrm{mL})\end{array}$ & $\begin{array}{l}\text { \% recovery } \\
(\text { mean } \pm \% R S D)\end{array}$ \\
\hline & & & 195951 & 5.959 & \\
\hline \multirow[t]{3}{*}{$50 \%$} & 4 & 2 & 198666 & 6.045 & $100.173 \pm 0.755$ \\
\hline & & & 198080 & 6.027 & \\
\hline & & & 257427 & 7.911 & \\
\hline \multirow[t]{3}{*}{$100 \%$} & 4 & 4 & 259554 & 7.978 & $99.077 \pm 0.588$ \\
\hline & & & 256740 & 7.889 & \\
\hline & & & 317558 & 9.820 & \\
\hline \multirow[t]{2}{*}{$150 \%$} & 4 & 6 & 320423 & 9.911 & $98.575 \pm 0.482$ \\
\hline & & & 318236 & 9.842 & \\
\hline
\end{tabular}


Table 4: Precision data of intra-day variability.

\begin{tabular}{|c|c|c|c|c|}
\hline $\begin{array}{l}\text { Concentration } \\
(\mu \mathrm{g} / \mathrm{mL})\end{array}$ & Area & $\%$ recovery & $S D$ & $\% R S D$ \\
\hline & 198331 & & & \\
\hline \multirow[t]{3}{*}{6} & 201079 & 101.442 & 0.765 & 0.754 \\
\hline & 200485 & & & \\
\hline & 257518 & & & \\
\hline \multirow[t]{3}{*}{8} & 262707 & 99.919 & 1.031 & 1.032 \\
\hline & 259859 & & & \\
\hline & 321415 & & & \\
\hline \multirow[t]{2}{*}{10} & 324315 & 99.804 & 0.481 & 0.482 \\
\hline & 322102 & & & \\
\hline \multicolumn{5}{|c|}{ Table 5: Precision data of inter-day variability. } \\
\hline \multirow[t]{2}{*}{$\begin{array}{l}\text { Concentration } \\
(\mu \mathrm{g} / \mathrm{mL})\end{array}$} & Area & $\%$ recovery & $S D$ & $\% R S D$ \\
\hline & 198485 & & & \\
\hline \multirow[t]{3}{*}{6} & 198988 & 100.337 & 0.800 & 0.797 \\
\hline & 196155 & & & \\
\hline & 260529 & & & \\
\hline \multirow[t]{3}{*}{8} & 263191 & 100.758 & 0.563 & 0.559 \\
\hline & 262707 & & & \\
\hline & 318986 & & & \\
\hline \multirow[t]{2}{*}{10} & 322102 & 99.240 & 0.520 & 0.524 \\
\hline & 321415 & & & \\
\hline
\end{tabular}

and very high precision of the developed chromatographic method.

\section{Robustness}

After varying the chromatographic parameters (flow rate, wavelength, and mobile phase composition) intentionally, no prominent alteration in the retention time was observed in the chromatogram (Fig. 6). A minor change (2-3\%) in the retention time was detected on enhancing or decreasing the parameters. The peak area (high), theoretical plates $(>2000)$, and the tailing factor $(<2 \%$ ) were found to meet the minimum requirements of the USP pharmacopeia. The study indicated that the developed chromatographic method possesses robust attributes.

\section{System Suitability Parameters}

The monitored system suitability parameters pointed toward a very high degree of reproducibility of the developed chromatographic method. The novel method at $10 \mu \mathrm{g} / \mathrm{mL}$ concentration had average retention time (Rt) of 5.416 minutes, mean peak area (PA) of
263,465 , mean theoretical plates (TP) of 2588, and tailing factor (TF) of 1.08 (Table 6). Which reflected towards high column efficacy, noteworthy resolution, good precision, better reproducibility, significant separation, and can be utilized for the routine pharmaceutical analysis. The chromatographic method meets the minimum essential requirements of US Pharmacopoeia monographs regarding theoretical plates (2000), tailing factor $(<2 \%)$, and presence of ideal Gaussian peak (symmetric $=$ asymmetric factor $=1)$.

\section{Limit of Detection and Quantification}

The LoD and LoQ of PRU were found to be $0.367 \mu \mathrm{g} / \mathrm{mL}$ and $1.111 \mu \mathrm{g} / \mathrm{mL}$, respectively, which indicated towards remarkable solute detection attribute of the developed chromatographic method. The method can possibly detect the lowest possible concentration of PRU in bulk or even in the formulation.

\section{Forced Degradation Studies}

The influence of photolytic effect, peroxide treatment, neutral condition, thermal environment, acidic treatment,

Table 6: Systems suitability parameters.

\begin{tabular}{llllll}
\hline Spiking & Rt $(\mathrm{min})$ & Conc. $(\mu \mathrm{g} / \mathrm{mL})$ & Area & Theoretical plates & Asymmetry \\
\hline 1 & 5.416 & 10 & 263465 & 2588 & 1.08 \\
2 & 5.418 & 10 & 263524 & 2629 & 1.11 \\
3 & 5.413 & 10 & 263208 & 2477 & 1.03 \\
4 & 5.411 & 10 & 262719 & 2416 & 1.06 \\
5 & 5.419 & 10 & 263591 & 2698 & 1.09 \\
Mean & 5.416 & 10 & 263302 & 2562 & 1.074 \\
\hline
\end{tabular}




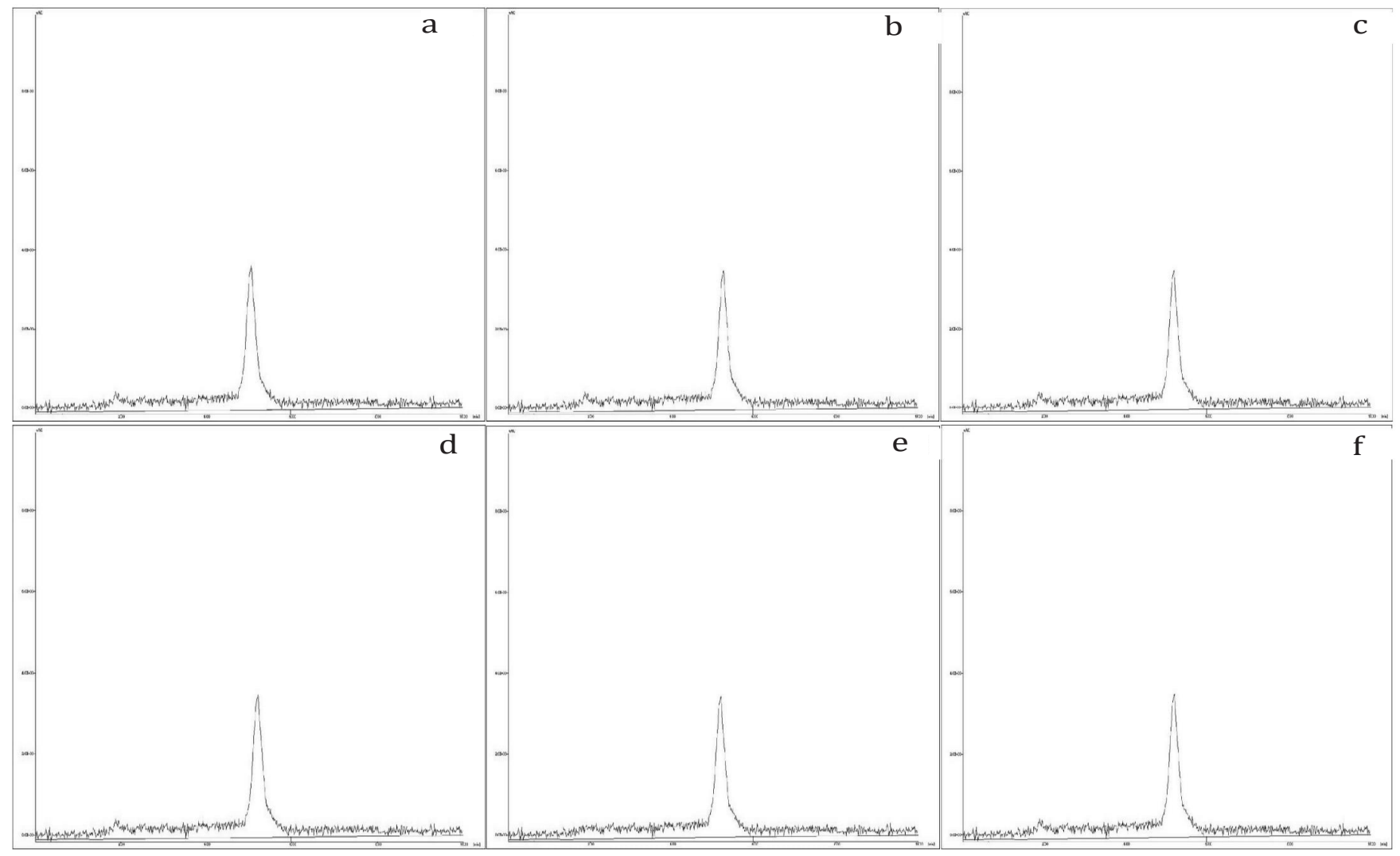

Fig. 6: Robustness studies of prucalopride succinate: (a) Flow rate at $0.9 \mathrm{~mL} / \mathrm{min}$; (b) Flow rate at $1.1 \mathrm{~mL} / \mathrm{min}$; (c) Wavelength at $275 \mathrm{~nm}$; (d) Wavelength at $279 \mathrm{~nm}$; (e) Mobile phase composition 18:82 v/v; and (f) Mobile phase composition 22:78 v/v

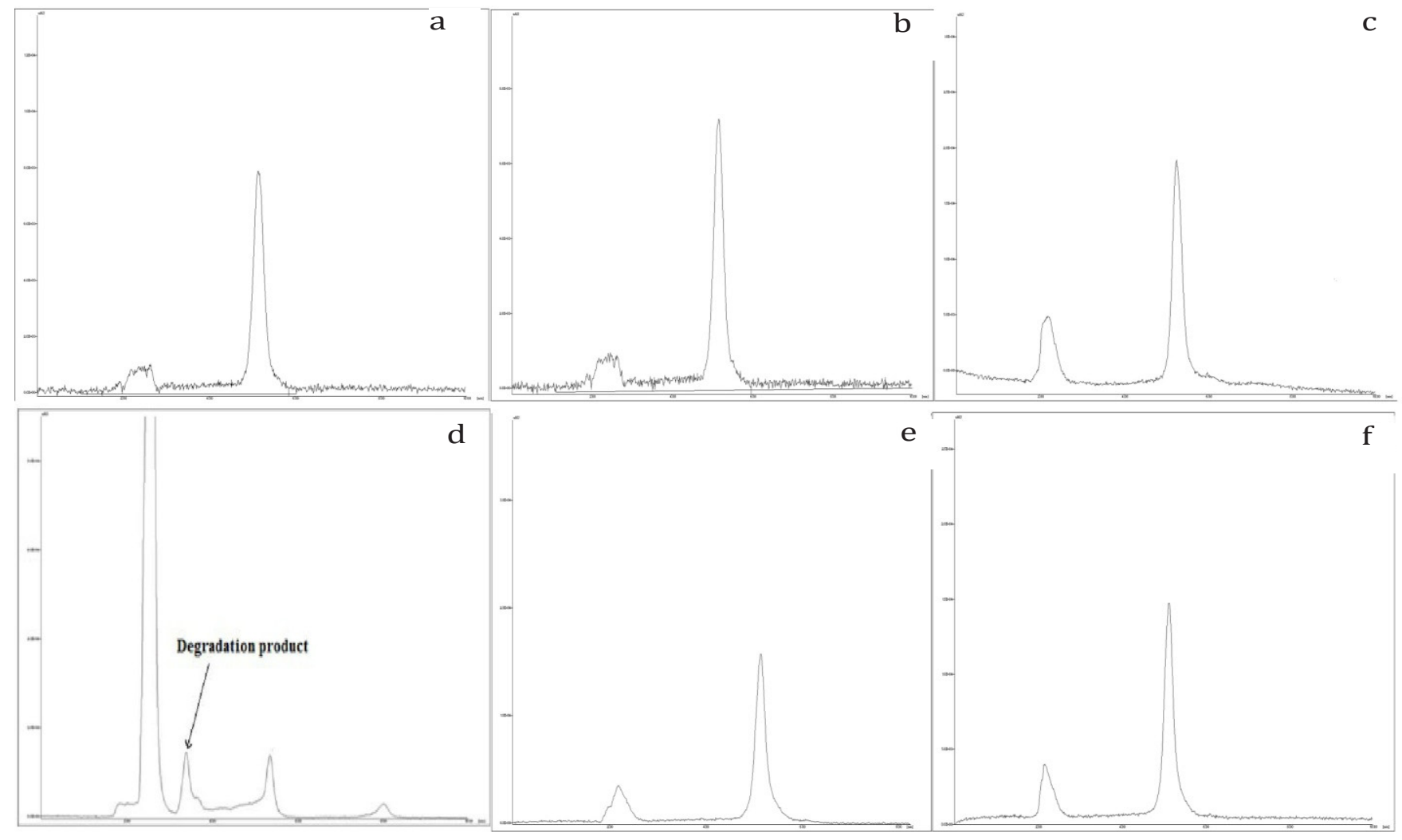

Fig. 7: Force degradation studies of prucalopride succinate: (a) Acidic condition; (b) Alkaline condition; (c) Neutral hydrolysis; (d) Oxidative condition; (e) Dry heat condition; and (f) UV-light 
and base treatment produced the formation of a degraded product at the Rt range of 2.1-3.4 minutes. While the acidic treatment and basic treatment did not produce any prominent peak in the forced degraded chromatogram, a distorted peak was observed in the Rt range of 2.1-2.3 minutes. In contrast to it, the chromatograms of neutral, oxidation, heat, and UV exposed samples demonstrated an eye-catching sharp peak at 2.148 minutes. The highest degradation was perceived under oxidative stress, where the degradants were located at Rt of 2.148 and 3.434 minutes (Fig. 7). Although, acidic and basic treatment has a well-established mechanism(s), however, the exact degradation mechanism through oxidative stress, the most prominent way is still unknown. But, it may be predicted that oxidative stress breaks the prevailing weak bonds and rapidly abstracted the protons from the drug substance.

\section{Comparison with Other Methods for Estimation of Prucalopride}

As there are no reported reverse-phase stability-indicating HPLC method previously developed or reported in any databases for the estimation of PRU in both bulk and tablet formulation, no comparison can be done in context to attributes such as accuracy, robustness, reproducibility, precision, and linearity. The method developed by us may be regarded as the "index RP-HPLC method" for the estimation of PRU. A few years back, researchers had estimated the content of PRU in rat plasma using ultra-high-performance liquid chromatography with tandem mass spectrometry method. ${ }^{[16]}$ This selective, rapid, accurate, and sensitive method comprising of acetonitrile-water (containing $0.1 \%$ formic acid) mobile phase system was found to have immense applications in pharmacokinetics. In comparison with our system, the method developed by our team for estimation of PRU in bulk might also be applied for estimating PRU in biological samples, particularly in rat plasma, maybe with reduced detection ability.

\section{CONCLUSION}

The developed validated chromatographic method can be used by the analytical chemists for quality assurance of the product in daily basis to estimate PRU in both bulk and tablet formulations due to high accuracy, robustness, reproducibility, precision, and linearity (the essential ICH-Q2A and Q2B requirements) as well as compliance with the minimum necessities of the US Pharmacopoeia monographs in terms of tailing values, \% RSD, and theoretical plates. The validated stress degradation studies (acid, oxidation, UV-induced, dry heat, neutral, and alkaline) revealed the possible degradants which will be beneficial for the quantification.

\section{REFERENCES}

1. Keating GM. Prucalopride: A review of its use in the management of chronic constipation. Drugs. 2013;73(17):1935-1950.

2. Garnock-Jones KP. Prucalopride: A review in chronic idiopathic constipation. Drugs. 2016;76(1):99-110.

3. Dongen V. Effect of prucalopride, a new enterokinetic agent, on gastrointestinal transit and anorectal function in healthy volunteers. Alim Pharmacol Therapeut. 1999;13(11):1493-1497.

4. Tack J, Corsetti M. Prucalopride: Evaluation of the pharmacokinetics, pharmacodynamics, efficacy and safety in the treatment of chronic constipation. Exp Opin Drug Metab Toxicol. 2012;8(10):1327-1335.

5. Tack J, Stanghellini V, Dubois D, Joseph A, Vandeplassche L, Kerstens R. Effect of prucalopride on symptoms of chronic constipation. Neurogastroenterol Motil. 2014;26(1):21-27.

6. Emmanuel AV, Roy AJ, Nicholls TJ, Kamm MA. Prucalopride, a systemic enterokinetic, for the treatment of constipation. Alim Pharmacol Therapeut. 2002;16(7):1347-1356.

7. Bassotti G, Gambaccini D, Bellini M. Prucalopride succinate for the treatment of constipation: An update. Exp Rev Gastroenterol Hepatol. 2016;10(3):291-300.

8. Deodhe S, Dhabarde DM, Kamble MA, Mahapatra DK. Development and validation of a novel stability indicating RP-HPLC method for the estimation of entecavir in tablet formulation. Eur J Anal Chem. 2017;12(3):223-235.

9. Deodhe S, Dhabarde DM, Kamble MA, Mahapatra DK. Novel stability indicating RP-HPLC method for the estimation of pinaverium bromide in tablet formulation: Assay development and validation. Eur J Anal Chem. 2017;12(2):3-16.

10. Kanthale SB, Thonte SS, Mahapatra DK. Development of validated stability indicating RP-HPLC method for the estimation of glecaprevir and pibrentasvir in bulk and pharmaceutical dosage form. J Appl Pharm Sci. 2019;9(6):52-60.

11. Sabale PM, Bhagwat D, Sabale VP, Mahapatra DK. Development and validation of RP-HPLC method for simultaneous estimation of esomeprazole and domperidone in capsule formulation. Eur J Anal Chem. 2018;13(6):57-66.

12. Jha SK, Bhaskaran S, Kamble MA, Mahapatra DK. A novel RP-HPLC based assay for the estimation of Tramadol $\mathrm{HCl}$ content in tablets: Development and Validation. Inventi Impact Pharm Anal Quality Assur. 2017; 2017(4):142-146.

13. Prakash O, Mahapatra DK, Singh R, Singh N, Verma N, Ved A. Development of a new isolation technique and validated RP-HPLC method for quercetin and kaempferol from azadirachta indica leaves. Asian J Pharm Anal. 2018;8(3):164-168.

14. Sawale V, Dhabarde DM, Mahapatra DK. Development and validation of UV spectrophotometric method for simultaneous estimation of olmesartan medoxomil and chlorthalidone in bulk and pharmaceutical dosage form. Eur J Anal Chem. 2017;12(1): 55-66.

15. Kanthale SB, Thonte SS, Mahapatra DK. Stability indicating RP-HPLC method for the simultaneous estimation of ivabradin and metoprolol in bulk and tablet formulation. J Appl Pharm Sci. 2019;9(4):137-144.

16. Sun Z, Zuo L, Kang J, Zhou L, Jia M, Li Z, Yang Z, Zhang X, Zhu Z. Development and validation of a sensitive UHPLC-MS/MS method for quantitation of prucalopride in rat plasma and its application to pharmacokinetics study. J Chromatograph. 2016;1033:328-333. 